Original Research
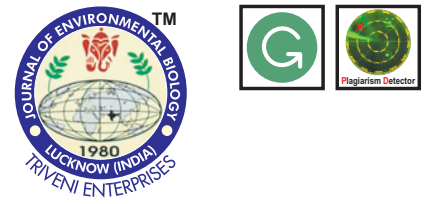

ISSN: 0254-8704 (Print) ISSN: 2394-0379 (Online) CODEN: JEBIDP

\title{
Determination of the energy, mass flow and temperature parameters in combustion systems of agricultural biomass residues
}

\section{Authors Info}

H. Unal and A. Kara

Department of Biosystems

Engineering, Faculty of Agriculture, University of Uludag, Nilufer,Bursa, 16059, Turkey

Department of Chemistry, Faculty of Arts and Science, University of Uludag, Nilufer, Bursa, 16059, Turkey

*Corresponding Author Email : hunal@uludag.edu.tr

Key words

Agricultural residues,

Biomass,

Combustion heat,

Corn cob,

Hazelnut shell

Publication Info

Paper received : 10.09 .2016

Revised received : 29.05.2017

Accepted : 28.06.2017

\section{Abstract}

Aim : This study was carried out to determine the energy, mass flow and temperature computations of agricultural biomass.

Methodology : The feasibility of the technique which enable to formulate a balanced chemical equation using the parameters of biomass moisture content and excess air utilized in combustion was determined for agricultural biomass residues (corn cob and hazelnut shell). The chimney gas composition was calculated assuming that carbon dioxide and water were completely consumed. The combustion temperature was obtained with an energy balance.

Results : Because of the error value of corn cob was negative, accepted combustion heat of this fuel was determined high $\left(1400^{\circ} \mathrm{K}\right)$ and concluded. It should have been reduced down to feasible value of this temperature. On the other hand, because of the error value for hazelnut shell was positive, raising the combustion heat is recommended. Feasible combustion heats for corn cob and hazelnut shell were $1389^{\circ} \mathrm{K}$ and $1437^{\circ} \mathrm{K}$, respectively. While heat of combustion of corn cob in dry basis was $1436^{\circ} \mathrm{K}$ for excess air parameter 1.0 , the heat of combustion in 0.5 moisture level was $1132^{\circ} \mathrm{K}$ with $27 \%$ reduction. The hazelnut shell combustion heat w a s a I so determined as $1205^{\circ} \mathrm{K}$ with about $23 \%$ reduction. The net heats of combustion of corn cob and hazelnut shells in wet basis were determined as 13,109 and $15,775 \mathrm{~kJ} \mathrm{~kg}^{-1}$, respectively.

Interpretation : The biomass moisture, excess air and heat losses from system were in accordance with each other.

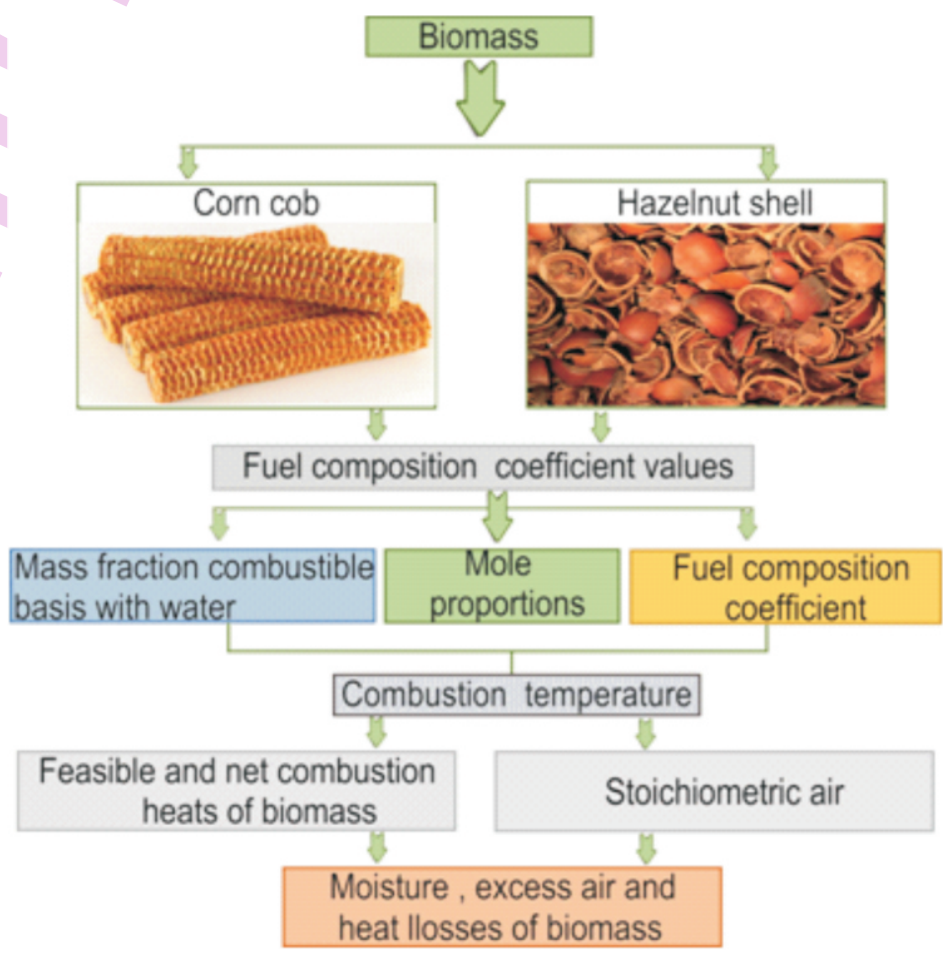




\section{Introduction}

Energy analysis has attracted increasing attention during recent decades, especially after the first "oil crisis" in 1973. Initially, a number of different methodologies and confusing nomenclature were used. This led to an international workshop in 1974, where the general outlines of energy analysis were laid down. Traditional energy analysis has been criticized from many points of view. The criticism concerns the suitability of using energy alone as a measure for resource use, as well as the fact that energy is not an unambiguous concept in the sense that different energy forms can be totalled. Also, the statement that all processes transform energy is self-evident according to fundamental thermodynamics. The main consideration is whether the energy obtained is useful or not (Nilsson, 1997).

The development of biomass combustion systems has increased dramatically since the energy shortages of the 1970's. One of the factors of concern in all combustion systems is efficiency (Payne, 1984; Kumar et al., 2002; Demirbas, 2004). However, before efficiency can be calculated the biomass energy entering the system must be determined. No comprehensive technique related to biomass has been found in the literature.

This technique requires knowledge of the biomass ultimate analysis, high measurement of heat combustion by a bomb calorimeter, the estimate of excess air amount and heat loss from the combustor (Payne, 1984). The calculation technique is based on three assumptions;

- biomass is completely combusted to $\mathrm{CO}_{2}$ and $\mathrm{H}_{2} \mathrm{O}$,

- sulphur and nitrogen contents are small and do not significantly affect oxidation reactions and

- ash content is significant but does not significantly affect oxidation reactions.

The aim of this study was to determine the feasibility of the technique developed by Payne (1984) in order to calculate the energy and mass flux in biomass combustion systems, also for agricultural residues. We have presented a balanced chemical equation describing the combustion of biomass, conducted an energy balance to determine combustion temperature, presented techniques for calculating other combustion parameters, and havepresented a sample calculation for agricultural biomass residues (corn cob and hazelnut shell).

\section{Materials and Methods}

Balanced chemical equations of biomass : Biomass composition is usually reported on wet or dry basis. In computations discussed by some researchers, it was used ona combustible basis, which is based on the dry composition free of ash, nitrogen, and sulphur, and thus, consisted only of the carbon, hydrogen and oxygen mass fractions (Payne, 1984;
Werther et al., 2000; Vassilev et al., 2010). Basing the calculation technique on the combustible fraction allows the calculation procedures to apply generally to biomass containing various quantities of ash or other inert materials. By this means, formulas presented in the study, will be practicable for different types of biomass.

The definitions for the mass fractions of carbon, hydrogen, oxygen, sulphur, ash, and water for wet, dry and combustible basis are listed in Table 1 (Payne, 1984; NASA, 2016; Vassilev et al., 2010). These mass fractions are calculated using the following equations (1a-1c):

$$
\begin{aligned}
& X^{0}=X /\left(1-X_{M}\right) \\
& X^{00}=X^{0} /\left(1-X_{S N A}^{0}\right) \\
& X_{S N A}^{0}=X_{S}^{0}+X_{N}^{0}+X_{A}^{0} \quad 1 \mathrm{~b}
\end{aligned}
$$

The moisture mass fraction must be expressed on a combustible basis to determine the proper ratio between water and combustible biomass in the combustion equation and is converted by the equation (1d):

$$
X_{M}^{00}=\frac{X_{M}}{1-X_{S N A}^{0}\left(1-X_{M}\right)} \quad 1 \mathrm{~d}
$$

An empirical mole of biomass arbitrarily normalized to one atom of carbon, i.e., $\mathrm{C}_{1} \mathrm{H}_{i} \mathrm{O}_{j}$, was used to describe the combustion of biomass with a chemical equation. The combustion of wet biomass with excess air is described by equation (2):

$$
\begin{aligned}
& \mathrm{C}_{1} \mathrm{H}_{i} \mathrm{O}_{j}+k\left(\mathrm{H}_{2} \mathrm{O}\right)+n_{e}\left[\mathrm{O}_{2}+\left(\frac{79}{21}\right) \mathrm{N}_{2}\right] \rightarrow \mathrm{CO}_{2} \\
& +\left(n_{e}-n\right) \mathrm{O}_{2}+\left(\frac{79}{21} n_{e}\right) N_{2}+\left(\frac{i}{2}+k\right) \mathrm{H}_{2} \mathrm{O}
\end{aligned}
$$

The coefficient $n$ given in equation (3) was determined from an oxygen balance of equation (2) for stoichiometric combustion of the biomass with air when $n_{e}$ equals $n$.

$$
n=1+\frac{i}{4}-\frac{J}{2}
$$

The fuel composition coefficients were calculated from the mass fractions. The derivation of equations for $i, j$, and $k$ is summarized in Table 1. The empirical mole of biomass is calculated as follows (Eq. 4a):

$$
M_{0}=1(12)+I(1.0)+j(16)
$$

The composition of the chimney gas was calculated based on equation (2) and summarized in Table 2. The mean molecular weight $M_{e}$ of the wet chimney gas was determined from the mole fractions in Table 2 using the equation (4b):

$$
M_{e}=44 Y_{\mathrm{CO}_{2}}+32 Y_{\mathrm{O}_{2}}+28 Y_{\mathrm{N}_{2}}+19 Y_{\mathrm{H}_{2} \mathrm{O}}
$$


Combustion temperature of biomass : A biomass combustion system must have among other requirements, a sufficient combustion temperature, to permit complete oxidation of the gaseous fuel. Combustion temperature is defined as the calculated temperature of the gaseous products of combustion resulting from combustion of a biomass containing a specified quantity of water, using a specified quantity of excess air, and having a specified system heat loss. The error associated with this assumption is determined in the calculation section. The combustion temperature is calculated using the first law of thermodynamics for a system at constant pressure with the equation:

$$
Q=H_{p}-H_{g}
$$

The total specific enthalpy of a species is the sum of the chemical and sensible enthalpies and is defined as:

$$
H_{i}^{0}=\Delta H_{f, 298, i}^{0}+\left(H_{T}^{0}-H_{298}^{0}\right)_{i}
$$

The total enthalpy of the reactants for one "kmol" of biomass, $M_{b}$, defined by equation (2) is calculated by multiplying the moles of each species by the total specific enthalpy and summing as equation (7):

$$
\begin{aligned}
& H_{r}=(1)\left[\Delta H_{f, 298, \text { Biomass }}^{0}+\left(H_{T_{0}}^{0}-H_{298}^{0}\right)_{\text {Biomass }}\right] \\
& +k\left[\Delta H_{f, 298, H_{2} O}^{0}+\left(H_{T_{0}}^{0}-H_{298}^{0}\right)_{H_{2} O}\right] \\
& -k[18 I]+n_{e}\left[\Delta H_{f, 298, O_{2}}^{0}+\left(H_{T_{0}}^{0}-H_{298}^{0}\right)_{O_{2}}\right] \\
& +\frac{79}{21} n_{e}\left[\Delta H_{f, 298, N_{2}}^{0}+\left(H_{T_{0}}^{0}-H_{298}^{0}\right)_{N_{2}}\right]
\end{aligned}
$$

It should be noted that the term $(18 \mathrm{k} \lambda)$ in equation (7) corrects the enthalpy of the reactants for the water in the biomass which is in liquid state.

The heat formation of biomass is needed in equation (7) and can be calculated using the high heat of combustion measured by the bomb calorimeter and the fuel composition coefficients. The heat or enthalpy of reaction with no moisture condensation is the difference between the enthalpy of formation of the products and enthalpy of formation of reactants at the reference temperature and at their standard state. Payne (1984) presented this thus:

$$
\Delta H_{T}=\sum_{i=1}^{\text {Prod }} n_{i}\left(\Delta H_{f, T, i}^{0}\right)-\sum_{i=1}^{\text {Re act }} n_{j}\left(\Delta H_{f, T, j}^{0}\right)
$$

The formula in equation (8a) was simplified and converted to in equation (8b) for the combustion of one mole of empirical biomass with oxygen at the reference temperature of $\Delta h_{298}\left(298^{\circ} \mathrm{C}\right)$.

$$
\Delta H_{\text {Reaction, } 298}^{0}=\sum_{i=1}^{\text {Prod }} n_{i}\left(\Delta H_{f, 298, i}^{0}\right)-\Delta H_{f, 298, \text { Biomass }}^{0}
$$

Equation (8b) was taken of final state which was arranged again with following equation:

$$
\Delta H_{f, 298, \text { Biomass }}^{0}=\sum_{i=1}^{\text {Prod }} n_{i}\left(\Delta H_{f, 298, i}^{0}\right)-\Delta H_{\text {Re action }, 298}^{0}
$$

The standard enthalpy of formation of biomass was calculated by balancing the equation (9) for the combustion of one empirical mole of biomass, calculating the enthalpy of the products, and subtracting the net heat of reaction.

$$
\mathrm{C}_{1} \mathrm{H}_{i} \mathrm{O}_{j}+n \mathrm{O}_{2} \rightarrow \mathrm{CO}_{2}+\frac{i}{2} \mathrm{H}_{2} \mathrm{O}
$$

The gross combustion heat $\Delta H_{298}$ was converted to energy per empirical mole of combustible biomass using the equation (10):

$$
\Delta H_{298, v}=\frac{\Delta H_{298} M_{b}}{1-X_{S N A}^{0}}
$$

The gross combustion heat at constant volume is corrected to constant pressure by adjusting for the change in number of moles in the bomb calorimeter is condensed. The change in number of moles is $1-n$ or, by substituting in equation (3) for $n$, it is $j / 2-i / 4$. Thus, the gross combustion heat at constant pressure was calculated as following equationequation (11):

$$
\Delta H_{298, p}^{0}=\Delta H_{298, v}+\left(\frac{j}{2}-\frac{i}{4}\right) R T
$$

The correction for converting the gross combustion heat from constant volume to constant pressure is very small relative to the heat of combustion and is negligible for most applications.

The net heat of reactions for a mole of dry combustible biomass was determinated by correcting the gross combustion heat measured at constant pressure by the bomb calorimeter for the latent heat of vaporization of the water generated during combustion as inequation(12):

$$
\Delta H_{\text {Reaction }, 298}^{0}=\Delta H_{298, p}^{0}+I(18)\left(\frac{i}{2}\right)
$$

The enthalpy of the products in equation (9) was calculated according tofollowing equation:

$$
\sum_{i=1}^{\text {Prod }} n_{i}\left(\Delta H_{f, 298, i}^{0}\right)=\left(\Delta H_{f, 298, \mathrm{CO}_{2}}^{0}\right)-\frac{i}{2} \Delta H_{f, 298, \mathrm{H}_{2} \mathrm{O}}^{0}
$$

Substituting the quantities evaluated by equations. (12, 13 ) into equation (8c) yielded the heat for formation of biomass. Then, it was used in equation (7) to calculate the total enthalpy of the reactants.

The total enthalpy of the products of combustion described by equation (2) is calculated using the following equation:

$$
H_{p}=\sum_{i=1}^{\operatorname{Prod}} n_{j}\left(\Delta H_{f, 298, j}^{0}+\left(H_{T_{c}}^{0}-H_{298}^{0}\right)_{j}\right)
$$

Since equation(14a) was expanded, it was converted into following equation: 
Table 1 : Mass fractions of biomass and derivation of the fuel composition coefficients

\begin{tabular}{|c|c|c|c|c|c|c|c|}
\hline Species & $\begin{array}{l}\text { Wet } \\
\text { basis }\end{array}$ & $\begin{array}{l}\text { Dry } \\
\text { basis }\end{array}$ & $\begin{array}{l}\text { Combustible } \\
\text { basis }^{(*)}\end{array}$ & $\begin{array}{l}\text { Mass fraction } \\
\text { combustible basis } \\
\text { with water }\end{array}$ & $\begin{array}{l}\text { Molecular } \\
\text { weight }\end{array}$ & Mol proportions & Fuel composition coefficients ${ }^{(1+)}$ \\
\hline $\bar{c}$ & $X_{c}$ & $X_{c}^{0}$ & $X_{c}^{\circ 0}$ & $X_{C}^{00}\left(1-X_{M}^{00}\right)$ & 12 & $X_{C}^{00}\left(1-X_{M}^{00}\right) / 12$ & 1 \\
\hline $\mathrm{H}$ & $X_{H}$ & $X_{H}^{\circ}$ & $X_{H}^{\circ 0}$ & $X_{H}^{00}\left(1-X_{M}^{00}\right)$ & 1.0 & $X_{H}^{00}\left(1-X_{M}^{00}\right) / 1$ & $i=12 X_{H}^{00} / X_{c}^{00}$ \\
\hline 0 & $X_{0}$ & $X_{0}^{0}$ & $X_{0}^{00}$ & $X_{0}^{00}\left(1-X_{M}^{00}\right)$ & 16 & $X_{0}^{00}\left(1-X_{M}^{00}\right) / 16$ & $j=(3 / 4) X_{0}^{00} / X_{c}^{00}$ \\
\hline $\mathrm{N}$ & $X_{N}$ & $X_{N}^{0}$ & - & - & - & - & - \\
\hline S & $X_{S}$ & $X_{S}^{0}$ & - & - & - & - & - \\
\hline Ash & $X_{A}$ & $X_{A}^{0}$ & - & - & - & - & - \\
\hline $\mathrm{H}_{2} \mathrm{O}$ & $X_{M}^{A}$ & - & $X_{M}^{\circ}$ & $X_{M}^{00}$ & 18 & $X_{M}^{00} / 18$ & $k=(2 / 3) X_{M}^{\circ 0} / X_{c}^{00}\left(1-X_{M}^{00}\right)$ \\
\hline$\overline{\text { Totals }}$ & 1.00 & 1.00 & $1.0+X_{M}^{00}$ & 1.00 & & & \\
\hline
\end{tabular}

Table 2 : Formulation of chimney gas composition

\begin{tabular}{lll}
\hline Gas specifies & Mol equation & Mol fraction equation \\
\hline $\mathrm{CO}_{2}$ & 1 & $\mathrm{Y}=1 / \Sigma$ \\
$\mathrm{O}_{2}$ & $\left(\mathrm{n}_{\mathrm{e}}-\mathrm{n}\right)$ & $\mathrm{Y}_{\mathrm{O}_{2}}=\left(\mathrm{n}_{\mathrm{e}}-\mathrm{n}\right) / \Sigma$ \\
$\mathrm{N}_{2}$ & $(79 / 21) \mathrm{n}$ & $\mathrm{Y}_{\mathrm{N}_{2}}=(79 / 21) \mathrm{n}_{\mathrm{e}} / \Sigma$ \\
$\mathrm{H}_{2} \mathrm{O}$ & $\mathrm{i} / 2+\mathrm{k}$ & $\mathrm{Y}_{\mathrm{H}_{2} \mathrm{O}}=(\mathrm{i} / 2+\mathrm{k}) / \Sigma$ \\
\hline Total & $\Sigma^{(0)}$ & \\
\hline
\end{tabular}

References: Gordon and Mcbride, 1976; Payne, 1984; Chase, 1998.

(") $\Sigma$ is the total moles of products in Eq. (2).

Table 3 : Polynominal coefficients for sensible enthalpy

\begin{tabular}{lllll}
\hline Coefficients & \multicolumn{4}{c}{ Gas specifies } \\
\hline & $\mathrm{CO}_{2}$ & $\mathrm{O}_{2}$ & $\mathrm{~N}_{2}$ & $\mathrm{H}_{2} \mathrm{O}$ \\
$\mathrm{a}_{0}$ & 2.25050 & 2.01660 & 2.01060 & 2.30280 \\
$\mathrm{a}_{1}$ & $6.15444 \mathrm{E} 3$ & $6.30100 \mathrm{E} 3$ & $6.45255 \mathrm{E} 3$ & $7.28867 \mathrm{E} 3$ \\
$\mathrm{a}_{2}$ & $5.54689 \mathrm{E} 6$ & $1.48669 \mathrm{E} 6$ & $7.61920 \mathrm{E} 7$ & $1.10216 \mathrm{E} 6$ \\
$\mathrm{a}_{3}$ & $1.69753 \mathrm{E} 9$ & $3.87270 \mathrm{E} 10$ & $4.80657 \mathrm{E} 11$ & $2.00326 \mathrm{E} 10$ \\
$\mathrm{a}_{4}$ & $2.00736 \mathrm{E} 13$ & $4.49134 \mathrm{E} 14$ & $9.27088 \mathrm{E} 15$ & $5.81217 \mathrm{E} 14$ \\
\hline
\end{tabular}

References: Gordon and Mcbride, 1976; Payne, 1984; Mcbride et al., 2001; Zehe et al., 2002

Table 4: Mass fractions of corn cob and hazelnut shell

\begin{tabular}{|c|c|c|c|c|c|c|}
\hline \multirow[t]{2}{*}{ Species } & \multicolumn{2}{|c|}{ Wet basis $(X)$} & \multicolumn{2}{|c|}{ Dry basis $\left(X^{\circ}\right)$} & \multicolumn{2}{|c|}{ Combustible basis $\left(\mathrm{X}^{\circ 0}\right)$} \\
\hline & Corn cob & Hazelnut shell & Corn $\operatorname{cob}^{(1)}$ & Hazelnut shell ${ }^{(")}$ & Corn cob & Hazelnut shell \\
\hline C & 0.3639 & 0.4092 & 0.4140 & 0.4650 & 0.4196 & 0.4734 \\
\hline $\mathrm{H}$ & 0.0524 & 0.0521 & 0.0596 & 0.0592 & 0.0604 & 0.0603 \\
\hline 0 & 0.4509 & 0.4030 & 0.5130 & 0.4580 & 0.5200 & 0.4663 \\
\hline $\mathrm{N}$ & 0.0012 & 0.0018 & 0.0014 & 0.0021 & -- & -- \\
\hline$S$ & 0.0018 & 0.0041 & 0.0020 & 0.0047 & -- & -- \\
\hline$S$ & 0.0018 & 0.0041 & 0.0020 & 0.0047 & -- & -- \\
\hline$A$ & 0.0088 & 0.0097 & 0.0100 & 0.0110 & -- & -- \\
\hline $\mathrm{H}_{2} \mathrm{O}$ & 0.1210 & 0.1200 & -- & -- & 0.1224 & 0.1219 \\
\hline Totals & 1.0000 & 1.0000 & 1.0000 & 1.0000 & $1+X_{M}^{\circ}$ & $1+X_{M}^{\infty 0}$ \\
\hline
\end{tabular}


Table 5 : Derivation of fuel composition coefficient values of the corn cob and hazelnut shell

\begin{tabular}{llllllll}
\hline Species & \multicolumn{2}{l}{$\begin{array}{l}\text { Mass fraction combustible } \\
\text { basis with water }\end{array}$} & $\begin{array}{l}\text { Molecular } \\
\text { weight }\end{array}$ & \multicolumn{2}{c}{ Mol proportions } & \multicolumn{2}{l}{ Fuel composition coefficients } \\
& Corn cob & Hazelnut shell & & Corn cob & Hazelnut shell & Corn cob & Hazelnut shell \\
\hline $\mathrm{C}$ & 0.3682 & 0.4157 & 12 & 0.0307 & 0.0346 & 1 & 1 \\
$\mathrm{H}$ & 0.0530 & 0.0529 & 1 & 0.0530 & 0.0529 & $\mathrm{i}=1.7275$ & $\mathrm{i}=1.5277$ \\
$\mathrm{O}$ & 0.4563 & 0.4095 & 16 & 0.0285 & 0.0256 & $\mathrm{j}=0.9293$ & $\mathrm{j}=0.7387$ \\
$\mathrm{H}_{2} \mathrm{O}$ & 0.1224 & 0.1219 & 18 & 0.0068 & 0.0068 & $\mathrm{k}=0.2217$ & $\mathrm{k}=0.1955$ \\
Total & 1.0000 & 1.0000 & & & & & \\
\hline
\end{tabular}

Table $6: n, n e, M b$ and Me values of corn cob and hazelnut shell

\begin{tabular}{llll}
\hline Parameters & Unit & Corn cob & Hazelnut shell \\
\hline $\mathrm{n}$ & - & 0.9672 & 1.0126 \\
$\mathrm{n}_{\mathrm{e}}$ & -- & 1.9344 & 2.0252 \\
$\mathrm{M}_{\mathrm{b}}$ & $\mathrm{kg} \mathrm{kmol}^{-1} \mathrm{C.b.}^{-1}$ & 28.5971 & 25.3471 \\
& & & \\
\hline
\end{tabular}

Table 7 : Computation values of gas compositions for corn cob and hazelnut shell

\begin{tabular}{llllll}
\hline Gas species & \multicolumn{2}{c}{ Mol value } & \multicolumn{2}{c}{ Mol fractions values } \\
\hline & Corn cob & Hazelnut shell & & Corn cob & Hazelnut shell \\
$\mathrm{CO}_{2}$ & 1 & 1 & $\mathrm{Y}_{\mathrm{CO}_{2}}$ & 0.0968 & 0.0944 \\
$\mathrm{O}_{2}$ & 0.967 & 1.013 & $\mathrm{Y}_{\mathrm{O}_{2}}$ & 0.0936 & 0.0956 \\
$\mathrm{~N}_{2}$ & 7.277 & 7.618 & $\mathrm{Y}_{\mathrm{N}_{2}}$ & 0.7045 & 0.7194 \\
$\mathrm{H}_{2} \mathrm{O}$ & 1.085 & 0.959 & $\mathrm{Y}_{\mathrm{H}_{2}}$ & 0.1051 & 0.0906 \\
Total & 10.329 & 10.590 & & 1.0000 & 1.0000 \\
\hline
\end{tabular}

Table 8: Combustion heats, enthalpies and error values of fuels

\begin{tabular}{|c|c|c|c|}
\hline Parameters & Unit & Corn cob & Hazelnut shell \\
\hline $\begin{array}{l}\Delta H_{298, v} \\
\Delta H_{298, p}^{o} \\
\Delta H_{\text {Reaction,298 }}^{o} \\
\sum_{i=1}^{\text {Prod }} n_{i}\left(\Delta H_{f, 298, i}^{o}\right) \\
\Delta H_{f, 298, B i o m a s s}^{o} \\
Q \\
H_{\mathrm{r}} \\
\mathrm{H}_{\mathrm{p}} \\
\text { Error }\end{array}$ & 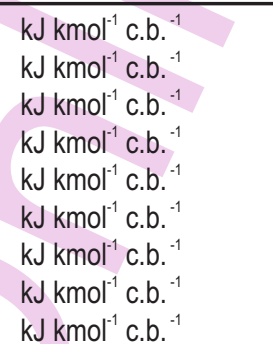 & $\begin{array}{l}480,000 \\
479,919 \\
441,952 \\
602,392 \\
160,440 \\
43,221 \\
223,790 \\
262,589 \\
-4,422\end{array}$ & $\begin{array}{l}504,774 \\
504,805 \\
471,230 \\
578,234 \\
107,004 \\
46,264 \\
162,877 \\
223,978 \\
14,837\end{array}$ \\
\hline
\end{tabular}

$$
\begin{aligned}
& H_{p}=1\left[\Delta H_{f, 298, \mathrm{CO}_{2}}^{0}+\left(H_{T_{C}}^{0}-H_{298}^{0}\right)_{\mathrm{CO}_{2}}\right] \\
& +\left(n_{e}-n\right)\left[\Delta H_{f, 298, \mathrm{O}_{2}}^{0}+\left(H_{T_{C}}^{0}-H_{298}^{0}\right)_{\mathrm{O}_{2}}\right] \\
& +\left(\frac{79}{21}\right) n_{e}\left[\Delta H_{f, 298, \mathrm{~N}_{2}}^{0}+\left(H_{T_{C}}^{0}-H_{298}^{0}\right)_{N_{2}}\right] \\
& +\left(\frac{i}{2}+k\right)\left[\Delta H_{f, 298, \mathrm{H}_{2} \mathrm{O}}^{0}+\left(H_{T_{C}}^{0}-H_{298}^{0}\right)_{\mathrm{H}_{2} \mathrm{O}}\right]
\end{aligned}
$$

The values of $\Delta H_{f, 29, i}^{0}$ were taken for $\mathrm{CO}_{2}, \mathrm{O}_{2}, \mathrm{~N}_{2}$ and $\mathrm{H}_{2} \mathrm{O}$ $393,510 \mathrm{~kJ} \mathrm{kmol}^{-1}, 0.000, \quad 0.000$ ve $241,826 \mathrm{~kJ} \mathrm{kmol}^{-1}$, respectively (Demirbas, 2004; NASA, 2016).

The values of enthalpy of formation and sensible enthalpies for $\mathrm{CO}_{2}, \mathrm{O}_{2}, \mathrm{~N}_{2}$ and $\mathrm{H}_{2} \mathrm{O}$ were taken from the JANAF tables (Chase, 1998). The coefficients for each gas species are given in Table 3. 
Table 9 : Convenient combustion temperatures and minimum error values for corn cob and hazelnut shells

\begin{tabular}{|c|c|c|c|c|c|c|}
\hline$X_{M}$ & $\begin{array}{l}=0.0 \\
\mathrm{~T}_{\mathrm{c}}\left({ }^{\circ} \mathrm{K}\right) \text { Error } \\
\text { Corn cob }\end{array}$ & $\begin{array}{l}\mathrm{T}_{\mathrm{c}}\left({ }^{\circ} \mathrm{K}\right) \text { Error } \\
\text { Hazelnut shell }\end{array}$ & $\begin{array}{l}=0.5 \\
\mathrm{~T}_{\mathrm{c}}\left({ }^{\circ} \mathrm{K}\right) \text { Error } \\
\text { Corn cob }\end{array}$ & $\begin{array}{l}\mathrm{T}_{\mathrm{c}}\left({ }^{\circ} \mathrm{K}\right) \text { Error } \\
\text { Hazelnut shell }\end{array}$ & $\begin{array}{l}=1.0 \\
\mathrm{~T}_{\mathrm{c}}\left({ }^{\circ} \mathrm{K}\right) \text { Error } \\
\text { Corn cob }\end{array}$ & $\begin{array}{l}\mathrm{T}_{\mathrm{c}}\left({ }^{\circ} \mathrm{K}\right) \text { Error } \\
\text { Hazelnut shell }\end{array}$ \\
\hline \multirow[t]{2}{*}{0.00} & 2163 & 2262 & 1710 & 1770 & 1436 & 1479 \\
\hline & 29.2 & 106.0 & -124.3 & 74.3 & 171.9 & -19.9 \\
\hline \multirow[t]{2}{*}{0.12} & 2056 & 2164 & 1643 & 1710 & 1389 & 1437 \\
\hline & -26.1 & 48.3 & -142.8 & 117.2 & -99.6 & -22.4 \\
\hline \multirow[t]{2}{*}{0.20} & 1975 & 2088 & 1591 & 1663 & 1351 & 1403 \\
\hline & -13.0 & -22.7 & -85.7 & -57.2 & 160.4 & 82.0 \\
\hline \multirow[t]{2}{*}{0.30} & 1857 & 1977 & 1513 & 1592 & 1295 & 1352 \\
\hline & -77.4 & -2.4 & 63.0 & 28.6 & -106.8 & 135.6 \\
\hline \multirow[t]{2}{*}{0.40} & 1716 & 1844 & 1418 & 1504 & 1224 & 1288 \\
\hline & -60.6 & -111.3 & -46.7 & 156.0 & -63.9 & 99.3 \\
\hline \multirow[t]{2}{*}{0.50} & 1544 & 1679 & 1298 & 1393 & 1132 & 1205 \\
\hline & 24.3 & 140.6 & -169.3 & -94.2 & 192.3 & -54.1 \\
\hline
\end{tabular}

Table 10 : Net combustion heats and stoichiometric air requirements of corn cob and hazelnut shell

\begin{tabular}{|c|c|c|c|}
\hline Parameters & Unit & Corn cob & Hazelnut shell \\
\hline$\overline{\Delta H_{298, N e t}^{0}}$ & $\mathrm{~kJ} \mathrm{kmol}^{-1} \mathrm{c} . \mathrm{b}^{-1}$ & 432,207 & 462,636 \\
\hline$\Delta H_{298, \text { Net }}$ & $\mathrm{kJ} \mathrm{kmol}^{-1}$ w.b. ${ }^{-1}$ & 14,914 & 17,926 \\
\hline$\Delta H_{\text {Net }}^{298, \text { vet }}$ & $\mathrm{kJ} \mathrm{kg}^{-1}$ w.b. ${ }^{-1}$ & 13,109 & 15,775 \\
\hline$\Delta H_{\mathrm{Net}}$ & $\mathrm{kJ} \mathrm{kg}^{-1} \mathrm{~d} \cdot \mathrm{b}^{-1}$ & 15,250 & 18,259 \\
\hline$\Delta H_{o}$ & $\%$ & 0.1046 & 0.1051 \\
\hline$Y_{O_{2}}^{o}$ & - & 0.993 & 1.003 \\
\hline$e$ & $\mathrm{~kg}$ air kg-1 fuel(w.b. $)^{-1}$ & 4.645 & 5.486 \\
\hline$S^{o o}$ & $\mathrm{~kg}$ air kg ${ }^{-1}$ fuel(d.b. $)^{-1}$ & 4.583 & 5.389 \\
\hline$S^{o}$ & -- & 2.0 & 2.0 \\
\hline
\end{tabular}

The variation of sensible enthalpies with temperatures between $100^{\circ} \mathrm{K}$ and $3000^{\circ} \mathrm{K}$ was described by a fourth order polynominal (Eq. 15) (Gordon and Mcbride, 1976; Payne, 1984; Mcbride et al., 2001; Zehe et al., 2002):

$$
\left(H_{T_{C}}^{o}-H_{298}^{o}\right)=4186.8\left[a_{0}+a_{1} T_{c}+a_{2} T_{C}^{2}+a_{3} T_{C}^{3}+a_{4} T_{C}^{5}\right]
$$

The procedure for calculating combustion temperature consists of assuming a combustion temperature and calculating the total enthalpies of the reactants and products. The temperature is readjusted until the error described by the equation(16) is sufficiently small for the desired accuracy.

$$
\text { Error }=Q-H_{p}+H_{r}
$$

Combustion Parameters of Biomass : The net heat of combustion of wet biomass is defined as a value calculated from the high heat of combustion of unit quantity at constant atmospheric pressure such that all water in the products remains in the form of vapour (Dogru et al., 1999; ASTM, 2002; Kumar et al., 2002; Gritzner and Auinger, 2009). It is calculated by correcting the high heat of combustion at constant pressure for both the water generated and existed in the biomass as follows (Eq. 17):

$$
\Delta H_{298, N e t}^{o}=\Delta H_{298, p}^{o}+I(18)\left(\frac{i}{2}+k\right)
$$

The net heat of combustion given by equation (17) is converted from a mole basis to mass basis by dividing by $M_{b}$ and to a dry basis by multiplying by $\left(1-X_{S N A}^{0}\right)$ or to a wet basis by multiplying by $\left(1-X_{S N A}^{0}\right)$ and $\left(1-X_{M}\right)$ Converting to a wet basis, neglecting the correction from constant volume to constant pressure, substituting the equations for the fuel composition coefficients $i, j$, and $k$, and rearranging, it can be shown that equation (18) converts to the following:

$$
\Delta H_{298, \text { Net }}=\left[\Delta H_{298}+9 / X_{H}^{o}+I \frac{X_{M}}{1-X_{M}}\right]\left(1-X_{M}\right)
$$

In equation (18), $9 \lambda X_{H}^{\circ}$ and $I \frac{X_{M}}{1-X_{M}}$ are correction for latent heat of the water exists in the biomass, respectively. This equation simplifies further to a more convenient form as equation (19).

The terms within the bracket are; the high heat of combustion measured by the bomb calorimeter, correction for latent heat of the water generated during combustion, and 
correction for latent heat of the water exists in the biomass, respectively.

$$
\Delta H_{\text {Net }}=\Delta H_{o}+\left(I-\Delta H_{o}\right) X_{M}
$$

Here, $\Delta \mathrm{H}_{0}$ is described by the equation:

$$
\Delta H_{o}=\Delta H_{298}+9 l X_{H}^{o}
$$

Excess air, $\varepsilon$ is defined as a multiple of the stoichiometric air requirements and is calculated by the following equation:

$$
e=\frac{n_{e}-n}{n}
$$

The value of $n_{e}$ in equation (21) is a measure of the level of excess air and is given by the following equation:

$$
n_{e}=n(e+1)
$$

The oxygen gas concentration is usually measured as volume fraction on a dry gas basis, $\mathrm{Y}_{\mathrm{O}_{2}}$ and is described by the following mole ratio using Eq. (23):

$$
Y_{O_{2}}^{o}=\frac{\left(n_{e}-n\right)}{1+\left(n_{e}-n\right)+\frac{79}{21} n_{e}}
$$

Substituting equation (22) for $n_{e}$ and solving for as a function of $\mathrm{Y}_{\mathrm{O}_{2}}^{\circ}$ yields (Eq. 24):

$$
e=\frac{Y_{O_{2}}^{o}}{0.21-Y_{O_{2}}^{o}}
$$

This equation is convenient for relating oxygen content to excess air for most purposes and has an error of only $1.5 \%$ for the sample calculation.

The stoichiometric air requirement, $S^{\circ}$, is defined as the mass of dry air required to burn a unit mass of dry fuel. The stoichiometric air requirement for the combustible fraction of the biomass fuel is estimated using equation (2) when $n_{e}$ equals $n$ to yield (Eq. 25):

$$
S^{o o}=\frac{n\left[32+\frac{79}{21}(28)\right]}{M_{b}}
$$

The stoichiometric air requirement for the dry of the biomass fuel is estimated using equation:

$$
S^{o o}=S^{o o}\left(1-X_{S N A}^{o}\right)
$$

The equivalence ratio $\phi$ is defined as the mass ratio of oxidant to fuel divided by the stoichiometric oxidant to fuel ratio, $S^{\circ 0}$. The equivalence ratio is most useful in describing gasification conditions but can also be applied to excess air combustion. The equivalence ratio was calculated as following:

$$
f=\frac{n_{e}\left[32+\frac{79}{21}(28)\right]}{\frac{M_{b}}{S^{00}}}=e+1
$$

By means of issued equations in methods, a program was designed in MS Excel allowing the definition of elemental analysis, energy and mass values (mole proportions, combustion heats, enthalpies, excess air coefficients, stoichiometric air demands, etc.) of different type biomass fuels that their heat of combustion and moisture contents were known. Thus, by means of energy and mass flux formula developed by Payne (1984), it was investigated whether or not the same results were obtained for agricultural residues. In this paper, the corn cob that has high current output in the world and the hazelnut shell that Turkey has a leading position at production were calculated as fuel. The ash, sulphur and nitrogen contents of fuels were low and moisture contents were selected close to each other.

\section{Results and Discussion}

On the basis of ultimate analysis (dry basis) of the corn $\mathrm{cob}$ and hazelnut shell agricultural biomass, wet basis and combustible basis mass fractions were calculated by course in Table 1 and using equations. (1a, 1b, 1c and 1d) (Table 4).

The heat of combustion $\Delta \mathrm{H}_{298}$ determined by calorimeter bomb for corn cob and hazelnut shell were 16,560 and 19,560 kJ $\mathrm{kg}^{-1}$ d.b..$^{-1}$, respectively.

The fuel composition coefficients ( $i$,jand $k$ ) were calculated using the equations in Table 1, and were given in Table 5.

The coefficient $n, n_{e}$ and molecular weight $M_{b}$ of the empirical mole of biomass were calculated using values in Table 5 and equations. (3, 4a and 22). The mean molecular weight of wet gas was determined from equation (4b) using mole fraction equations in Table 2. Total results are shownin Table 6.

The mass fractions of the corn cob and hazelnut shell in mean molecular weight equations of wet chimney gas were calculated with respect to Table 2 and are given in Table 7.

The sensible enthalpy of the dry biomass was calculated using the equation $\quad\left(H_{T_{o}}^{o}-H_{298}^{o}\right)_{B i o m a s s}=\int_{298}^{T_{o}^{o}} C_{p} M_{b} d T$.

Dry biomass sensible enthalpy was calculated with $\left(H_{T_{o}}^{o}-H_{298}^{o}\right)_{\text {Biomass }}=\int_{298}^{T_{o}} C_{p} M_{b} d T$ eqation. In this calculation; $c_{p}=3.35 X_{m}+0.84 \mathrm{kmol}^{-10} \mathrm{~K}^{-1}\left(X_{m}=0\right.$ için $)$ equation was used.

With the transformation of the heat of combustion inequation (10), $\Delta \mathrm{H}_{298}$ and making use of equation(11), $\Delta \mathrm{H}_{298, \mathrm{p}}$ was obtained. The net heat of reaction $\left(\Delta \mathrm{H}_{\text {Reaction,298 }}^{\circ}\right)$ and the enthalpy of products $\sum_{i=1}^{\text {Prod }} n_{i} \Delta H_{f, 29, i}^{o}$ were calculated in equations. (1213), respectively. Thus, the standart entalphy of biomass $\left(\Delta H_{f, 298, \text { Biomass }}^{\circ}\right)$ was determined by using equation (8c). Then, exploiting equation 
(7), total enthalpy of reactants $\left(H_{r}\right)$ at $T_{0}\left(298^{\circ} \mathrm{K}\right)$ and also assuming $T_{c}$ was $1400^{\circ} \mathrm{K}$ and using equation(14b), total enthalpy of products $\left(H_{p}\right)$ were established.

In most of the combustion systems, energy loss occurs and $Q$ is negative. When ten percent of net heat of combustion calculated from equation (17) was presumed loss heat, error value was obtained. Error value was calculated according to equation (16). As can be seen in Table 8 , because of the error value of corn cob was negative, accepted combustion heat of this fuel was found a little high $\left(1400^{\circ} \mathrm{K}\right)$ and concluded that $T_{c}$ should have been reduced down to feasible value. For hazelnut shell, error value was positive so increasing the combustion heat was necessary.

When error value was about $200 \mathrm{~kJ} \mathrm{kmol}^{-1}$, temperature estimation was affected at the rate of $1^{\circ} \mathrm{K}$. Accordingly, calculated combustion heat for corn cob and hazelnut shell were $1389^{\circ} \mathrm{K}$ and $1437^{\circ} \mathrm{K}$, respectively. Provided that heat loss, end analysis and excess air parameter were same, calculated heat of combustion for corn cob and hazelnut shell having 0.3 moisture mass fractions were $1295^{\circ} \mathrm{K}$ ve $1352^{\circ} \mathrm{K}$, respectively (Table 9).

For moisture mass fractions changed between $0.0 \%$ and $50.0 \%$ and also all heat of combustion for excess air parameters $0.0,0.5$ and 1.0 were calculated in developed MS Excel program (Table 9). Table 9 also included minimum error values that consistent combustion heat was obtained.

Table 9 shows thatwhile heat of combustion of corn cob in dry basis $\left(X_{m}=0.0\right)$ was $2163^{\circ} \mathrm{K}$ when excess air parameter was 0.0 , the heat of combustion in 0.5 moisture level was $1544^{\circ} \mathrm{K}$ with forty per cent decreasing. The hazelnut shell combustion heat was also determined about $35 \%$ decreasing as $1679^{\circ} \mathrm{K}$. While heat of combustion of corn cob in dry basis was $1436^{\circ} \mathrm{K}$ for excess air parameter 1.0 , the heat of combustion in 0.5 moisture level was $1132^{\circ} \mathrm{K}$ with $27 \%$ reduction. The hazelnut shell combustion heat was also determined as $1205^{\circ} \mathrm{K}$ with about $23 \%$ reduction. The calculated combustion temperature values in Table 9 were consistent with that of Payne (1984) calculated for wood chips fuel.

The net combustion heats of corn cob and hazelnut shell residues $\left(\Delta \mathrm{H}_{\text {Net }}\right)$ were calculated by means of equations. (20-21) and presented in Table 10. As can be seen from Table 10, the net heats of combustion of corn cob and hazelnut shell in wet basis were determined as 13,109 and $15,775 \mathrm{~kJ} \mathrm{~kg}^{-1}$, respectively. Volume fractions of the substance in chimney gas calculated according to equations in Table 2 and presented in Table 10.

Stoichiometric air amount (dry basis) necessary for the burning of corn cob and hazelnut shell were obtained 4.583 ve $5.389 \mathrm{~kg}$ air kg ${ }^{-1}$ fuel and excess air values were calculated as 0.993 and 1.003, respectively. The obtained results were comparable to that of Payne (1984) calculated for wood chips.

\section{Acknowledgment}

The authors are thankful to the Head, Department of Chemistry, Faculty of Arts and Science, University of Uludag for providing necessary facilities and resources to conduct the experiment.

\section{References}

ASTM. : Annual Book of ASTM Standards. American Society for Testing and Materials, Philadelphia, PA, 19103 (2002).

Chase, M.W. : NIST-JANAF Thermochemical Tables. 4th edn., J. Phys. Chem. Ref. \{Data Monograph No. 9$\}$ (1998).

Demirbas,A:: Combustion characteristics of different biomass fuels. Prog. Energ. Combust., 30, 219-230 (2004).

Dogru, M., C.R. Howarth, G. Akay, B. Keskinler and A.A. Malik : Gasification of hazelnut shells in a downdraft gasifier. Energy, 27, 415-427 (2002).

Dogru, M., C.R. Howarth, A.A. Malik and H. Olgun : A study of bio-nut shells for gasification. Oxford, UK: Elsevier Science Ltd., Oakland, California, USA, pp. 1051-1057 (1999).

Gordon, S. and B.J. Mcbride : Computer program for calculation of complex chemical equilibrium compositions, rocket performance, incident and reflected shocks and Chapman-Jouguet detonations. NASASP-273, (Revision of 1971 publication), (1976).

Gritzner, G. and M. Auinger : Statistical analysis of gibbs energies of transfer of cations and soft solvent parameters. Acta Chim. Slov., 56, 86-94 (2009).

Kumar, A., P. Purohit, S. Rana and T.C. Kandpal : An approach to the estimation of the value of agricultural residues used as biofuels. Biomass Bioenerg., 22, 195-203 (2002).

Mcbride, B.J., S. Gordon and M. Reno : Thermodynamic data for fifty reference element. NASA Technical Paper 3287/REV1, p. 249 (2001).

NASA.: Chemical compounds. NASA ThermoBuild, (http://www.grc.nasa.gov/WWW/CEAWeb/ ceaThermoBuild.htm) Accessed 29 July 2016, (2016).

Nilsson, D. : Energy, exergy and emergy analysis of using straw as fuel in district heating plants. Biomass Bioenerg., 13, 63-73 (1997).

Payne F.A. : Energy and mass flow computation in biomass combustion systems. T.ASAE, 27, 1532-1541 (1984).

Vassilev,S.V., D. Baxter, L.K. Andersen and C.G. Vassileva: An overview of the chemical composition of biomass. Fuel, 89, 913-933 (2010).

Werther,J., M. Saenger, E.U. Hartge, T. Ogada and Z. Siagi: Combustion of agricultural residues. Prog. Energ. Combust., 26, 1-27 (2000).

Zehe, M.J., S. Gordon and B.J. Mcbride : CAP: A computer code for generating tabular thermodynamic functions from NASA lewis coefficients. NASA/TP-210959/Rev1, p. 84 (2002). 


\section{Nomenclature}

$\mathrm{C}, \mathrm{H}, \mathrm{O}, \mathrm{N}, \mathrm{S}, \mathrm{A}$

$C_{p}$

$n, n_{e}, n_{i}, n_{j}$

$\mathrm{H}_{p}$

$\mathrm{H}$.

$H_{T, i}^{o}$

$H_{298, i}^{\circ}$

$\left(H_{T_{0}}^{\circ}\right.$

$\left.-H_{298}^{\circ}\right)_{\text {Biomass }}$

$\mathrm{i}, \mathrm{j}, \mathrm{k}$

$\mathrm{Mb}_{\mathrm{b}}$

$\mathrm{Me}$

$\mathrm{R}$

Q

$\mathrm{S}^{\circ}$

$S^{\circ 0}$

$\mathrm{T}$

$\mathrm{T}_{0}$

$T_{0}$

$\mathrm{X}$

$Y$

$\lambda$

$\varepsilon$

$\Delta H_{f, 298, \text { Biomass }}^{\circ}$

$\Delta H_{f, 298, i}^{\circ}$

$\Delta H_{\text {Reaction, } 298}^{\circ}$

$\sum^{\text {Prod }}$

$\sum_{i=1}^{\text {Prod }} n_{i}\left(\Delta H_{f, 298, i}^{\circ}\right)$

$\Delta H_{298}$

$\Delta H_{298, p}^{\circ}$

$\Delta H_{298, v}$

$\Delta H_{\text {Net }}$

$\Delta H_{0}$

Superscripts

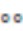

\section{Abbreviation}

c.b.

d.b.

w.b.
Carbon, Hydrogen, Oxygen, Nitrogen, Sulphur, Ash

Specific heat of biomass which was estimated by Siebel's equation

Number of moles, kmol

Total enthalpy of the products, $\mathrm{kJ} \mathrm{kmol}^{-1}$

Total enthalpy of the reactants, $\mathrm{kJ} \mathrm{kmol}^{-1}$

Sensible enthalpy of species $i$ at a temperature $T$ and at the standard thermodynamic state, $\mathrm{kJ} \mathrm{kmol}^{-1}$

Sensible enthalpy of species $i$ at $298^{\circ} \mathrm{K}$ and at the standard thermodynamic state, $\mathrm{kJ} \mathrm{kmol}^{-1}$

Sensible enthalpy of the dry biomass, $\mathrm{kJ} \mathrm{kmol}^{-1}$

Fuel composition coefficients, --

Molecular weight of the empirical mole of biomass, $\mathrm{kg} \mathrm{kmol}^{-1}$

Mean molecular weight of the wet gas, $\mathrm{kg} \mathrm{kmol}^{-1}$

Universal gas constant, $8.319 \mathrm{~kJ} \mathrm{kmol}^{-1}{ }^{\circ} \mathrm{K}^{-1}$

Heat loss calculated or estimated for the particular system under consideration, $\mathrm{kJ} \mathrm{kmol}^{-1}$

Stoichiometric air requirement of dry biomass, $\mathrm{kg}$ air $\mathrm{kg}^{-1} \mathrm{d.b} .{ }^{-1}$

Stoichiometric air requirement for the combustible fraction of the biomass fuel, $\mathrm{kg} \mathrm{air} \mathrm{kg}^{-1} \mathrm{c.b} .{ }^{-1}$

Temperature at which the bomb calorimeter test, ${ }^{\circ} \mathrm{K}\left(298^{\circ} \mathrm{K}\right)$

Combustion temperature, ${ }^{\circ} \mathrm{K}$

Ambient temperature, ${ }^{\circ} \mathrm{K}\left(298^{\circ} \mathrm{K}\right)$

Mass fraction

Volume fraction on the dry gas basis

Latent heat of vaporization of water at the reference temperature of $298^{\circ} \mathrm{K} \mathrm{kJ} \mathrm{kg}^{-1}\left(2442 \mathrm{~kJ} \mathrm{~kg}^{-1}\right.$ for water at $\left.298^{\circ} \mathrm{K}\right)$

Excess air

Standard enthalpy of formation of biomass, $\mathrm{kJ} \mathrm{kmol}^{-1}$

Standard enthalpy of formation at the standard thermodynamic state of 1 atmosphere pressure and temperature of $298^{\circ} \mathrm{K}$ for species, $\mathrm{kJ} \mathrm{kmol}^{-1}$

Net heat of reaction for a mole of dry combustible biomass, $\mathrm{kJ} \mathrm{kmol}^{-1}$

Enthalpy of products, $\mathrm{kJ} \mathrm{kmol}^{-1}$

Heat of combustion measured from bomb calorimeter of dry biomass, $\mathrm{kJ} \mathrm{kg}^{-1}$

Gross combustion heat at constant pressure, $\mathrm{kJ} \mathrm{kmol}^{-1}$

Gross combustion heat at constant volume, $\mathrm{kJ} \mathrm{kmol}^{-1}$

Net heat of combustion of biomass as a function of mass fraction moisture, $\mathrm{kJ} \mathrm{kg}^{-1}$

Net heat of combustion at zero biomass moisture content, $\mathrm{kJ} \mathrm{kg}^{-1}$

Indicates quantities is on a moisture-free basis or, for enthalpy, standard thermodynamic state

Indicates quantity is on a combustible basis

combustible basis

dry basis

wet basis 